НАУЧНЫЕ АРХИВЫ

УДК 911.2:556.16

ISSN 1609-0683

DOI: https://doi.org/10.17308/geo.2021.4/3762

Вариация стока и его факторов ${ }^{1}$

\author{
Н. П. Чеботарев \\ профессор, доктор технических наук \\ Воронежский государственный университет \\ Воронеж, 1949
}

\begin{abstract}
Аннотация: Редакция журнала «Вестник ВГУ. Серия: География. Геоэкология» публикует монографию Н. П. Чеботарева «Вариация стока и его факторов». Проблема, поднятая автором в середине $\mathrm{XX}$ века, актуальна и сегодня. Однако монография Н. П. Чеботарева стала библиографической редкостью уже сразу после выхода в свет.

Текст книги воспроизводится в авторском варианте. Для понимания важности проблемы в современных исследованиях в области гидрологии публикацию книги предваряет комментарий кандидата географических наук С. Д. Дегтярева (Вестник ВГУ. Серия: География. Геоэкология, 2018, № 3).
\end{abstract}

Ключевые слова: речной сток, вариация стока, факторы стока.

Для цитирования: Чеботарев Н.П. Вариация стока и его факторов // Вестник Воронежского государственного университета. Серия: География. Геоэкология, 2021, № 4, с. 135-136. DOI: https://doi. org/10.17308/geo.2021.4/3762

\section{4. ВАРИАЦИИ ПРОДОЛЖИТЕЛЬНОСТИ ПО- ЛОВОДЬЯ}

Для случая одновременного снеготаяния по бассейну продолжительность половодья Т должна зависеть от продолжительности снеготаяния $\mathrm{t}_{\mathrm{c}}$, от времени добегания $\tau$ и от времени регулирования $-\mathrm{t}_{\mathrm{p}}$, т.е.

$$
\mathrm{T}=\mathrm{t}_{\mathrm{c}}+\tau+\mathrm{t}_{\mathrm{p}} .
$$

Ранее мной была выведена формула для интенсивности снеготаяния, которую можно переписать так:

откуда

$$
\mathrm{x}+1=\mathrm{x}_{0} 1^{-\mathrm{kt}}=\frac{\mathrm{x}_{0}}{\mathrm{l}^{\mathrm{kt}}}
$$

$$
\mathrm{t}_{\mathrm{c}}=2.3 \frac{1}{\mathrm{k}} \lg \left(\frac{\mathrm{x}_{0}}{\mathrm{x}+1}\right)
$$

При $\mathrm{x}=0 \quad \mathrm{t}_{\mathrm{c}}=2,3 \frac{1}{k} \lg \mathrm{x}_{0}$

где $\mathrm{k}=\mathrm{k} 0+\mathrm{C}\left[1 \sum(\theta+2)\right]^{\mu}$ где, $\mu>1$.

Из последнего равенства следует, что продолжительность снеготаяния зависит от первоначального запаса воды в снеге $\left(\mathrm{x}_{0}\right)$ и от суммы положительных температур от начала снеготаяния $\sum(\theta+2)$.

При этом $\mathrm{t}_{\mathrm{c}}$ растет с увеличением $\mathrm{x}_{0}$ и убывает с увеличением $\sum(\theta+2)$. Так как обе величины $\mathrm{x}_{0}$ и $\sum(\theta+2)$ являются величинами случайными, то, следовательно, и продолжительность снеготаяния $-t_{c}$ является случайной переменной величиной.

Время добегания зависит от геометрических размеров бассейна и от скорости стекания. Но скорость движения талых вод зависит, помимо морфологических особенностей (постоянные для каждого бассейна), а также и от интенсивности снеготаяния, которая является случайной переменной величиной. Но последняя зависит, в свою очередь, от тех же случайных величин, как и $\mathrm{t}_{\mathrm{c}}$, т.е. от $\mathrm{x}_{0}$ и $\sum(\theta+2)$.

Время регулирования $-t_{p}$ зависит от регуляционных свойств бассейна: озерности, болотистости, формы полого русла и др.

Исходя из известного уравнения водного баланса, регулирующего сток водоема, можно прийти к виду уравнения

(C) Чеботарев Н.П., 2021

${ }^{1}$ Продолжение. Начало в журналах «Вестник ВГУ. Серия: География. Геоэкология» № 3/2018 г., № 4/2018 г., № 1/2019 г., № 2/2019 г., № 3/2019 г., № 4/2019 г., № 1/2020 г., № 2/2020 г., № 3/2020 г., № 4/2020 г., № 1/2021 г., № 2/2021 и № 3/2021.

Контент доступен под лицензией Creative Commons Attribution 4.0 License.

Вестник ВГУ, Серия: География. Геоэкология, 2021, № 4, 135-136 


$$
\mathrm{y}_{\mathrm{n}}-\mathrm{y}_{\mathrm{c}}=\mathrm{S} \gamma
$$

где $\mathrm{S}$ - озерность в долях от площади бассейна, a $\gamma=\frac{\Delta \mathrm{h}}{\Delta \mathrm{t}} \mathrm{y}_{\mathrm{n}}$ и $\mathrm{y}_{\mathrm{c}}-$ приток и сток из водоема.

Выражение $\mathrm{S} \gamma$ представляет собой характеристичный безразмерный параметр, характеризующий регулирующую способность водоема.

Слагаемое $\mathrm{t}_{\mathrm{p}}$ является функцией $\mathrm{S} \gamma$ и в первом приближении примем, что $\mathrm{t}_{\mathrm{p}}=\mathrm{kS} \gamma$.

В этом слагаемом варьирующей величиной является $\gamma$, но она зависит также от интенсивности снеготаяния, а, следовательно, вариация продолжительности половодья в целом зависит от первоначального запаса воды в снеге $\mathrm{x}_{0}$ и суммы положительных температур за период снеготаяния. Первое слагаемое $t_{c}$ оказывает наибольшее влияние на вариацию величины $\mathrm{T}$, так как оно полностью является случайной переменной величиной, тогда как второе и третье - частично. Принимая во внимание, что и эти последние зависят от тех же случайных факторов, как и первое, можно допустить, что $\mathrm{C}_{\mathrm{vT}} \cong \mathrm{C}_{\mathrm{vtc}}$. Так как для $\mathrm{t}_{\mathrm{c}}$ нам известно выражение (128) и допуская, что между $\mathrm{x}_{0}$ и $\sum(\theta+2)$ зависимость слаба, которой можно пренебречь, мы вправе написать выражение для дисперсии

$$
\begin{gathered}
{ }_{\mathrm{T}^{2}}=\mu_{1}^{2} \sigma_{x_{0}}^{2}+\mu_{2}^{2} \sigma^{2} \sum \theta \\
\text { где } \mu=\frac{\partial \mathrm{f}}{\partial \mathrm{x}_{0}} \text { и } \mu_{2}=\frac{\partial \mathrm{f}}{\partial \sum \theta} \text { откуда } \\
\mathrm{C}_{\mathrm{vT}}=\sqrt{\mu_{1}^{2} \mathrm{k}_{1}^{2} \mathrm{C}_{\mathrm{v}}^{2} \mathrm{x}_{0}+\mu_{2}^{2} \mathrm{k}_{2}^{2} \mathrm{C}_{\mathrm{v}}^{2 \sum \theta}}
\end{gathered}
$$

где

$$
k_{1}=\frac{\bar{x}_{0}}{\bar{T}}, k_{2}=\frac{\overline{\Sigma(\theta+2)}}{\bar{T}} .
$$

Вариация продолжительности половодья может иметь практическое значение, когда является надобность в построении гидрографа половодья, а также во всех других случаях, когда необходимо характеризовать вариацию величины - Т.

\title{
SCIENTIFIC ARCHIVES
}

UDC 911.2:556.16

ISSN 1609-0683

DOI: https://doi.org/10.17308/geo.2021.4/3762

\section{Variation of Runoff and its Factors}

\author{
N. P. Chebotarev \\ Doctor of Sciences in Technology \\ Voronezh State University \\ Voronezh, 1949
}

\begin{abstract}
The editorial board of the journal «Bulletin of VSU. Series: Geography. Geoecology» publishes the monograph of N. P. Chebotarev «Variation of runoff and its factors». The issue raised by the author in the middle of the 20th century is still relevant today. However, the monograph of N. P. Chebotarev became a bibliographic rarity immediately after the publication.

The text of the book is reproduced in the author's version. To understand the importance of the problem in modern research in the field of hydrology, the publication of the book is preceded by a comment by S. D. Degtyarev - candidate of geographical sciences (Vestnik Voronezskogo gosudarstvennogo universiteta. Seria: Geografia. Geoekologia, 2018, no. 3).

Key words: river runoff, runoff variation, runoff factors.

For citation: Chebotarev N.P. Variation of Runoff and its Factors. Vestnik Voronezskogo gosudarstvennogo universiteta. Seria: Geografia. Geoekologia, 2021, no. 4, pp. 135-136. (In Russ.) DOI: https://doi.org/10.17308/ geo.2021.4/3762
\end{abstract}

(C) Chebotarev N.P., 2021

(c) (i) The content is available under Creative Commons Attribution 4.0 License. 